\title{
ESTADO ENERGÉTICO DA ÁGUA NA SEMENTE DE MILHO NO PROCESSO DE GERMINAÇÃO ${ }^{1}$
}

\author{
FRANCISCO AMARAL VILLELA ${ }^{2,4, *}$, JULIO MARCOS FILHO ${ }^{3,4}$, ANA DIONISIA DA LUZ COELHO NOVEMBRE
}

\begin{abstract}
RESUMO - Este trabalho foi desenvolvido com o objetivo de estudar as modificações do estado da água na semente de milho no processo de germinação, com destaque para o comportamento do potencial hídrico do embrião e do teor de água da semente inteira e de suas estruturas funcionais. Foram utilizadas sementes de milho, cultivares Zeneca 8330 e 8420, cada um representado por dois lotes, com diferentes potenciais fisiológicos. Para o estabelecimento da marcha de absorção de água da semente e de suas partes (embrião e cariopse sem embrião) e o monitoramento periódico do potencial hídrico do embrião, as sementes foram submetidas à hidratação sob condições de plena disponibilidade hídrica. Os graus de umidade foram obtidos pela pesagem de 100 sementes e, para os embriões e as cariopses sem embrião, foram avaliados pelo método da estufa $\left(105 \pm 3^{\circ} \mathrm{C} / 24 \mathrm{~h}\right)$. Os potenciais hídricos dos embriões foram determinados através de psicrômetro termopar, tipo multivoltímetro, modelo Wescor HR-33T, operando pelo método do ponto de orvalho. Os resultados permitiram constatar que, apesar de absorver menor quantidade de água, o embrião hidrata com velocidade superior à cariopse sem embrião. Na fase de embebição, os embriões das sementes dos lotes de menor potencial fisiológico absorvem quantidade de água superior aos das sementes dos lotes de maior potencial fisiológico. Na retomada do crescimento embrionário, ocorre similaridade de potenciais hídricos nos embriões, entre cultivares e entre lotes com diferentes potenciais fisiológicos.
\end{abstract}

Termos para indexação: Zea mays, embebição, potencial hídrico, potencial fisiológico.

\section{IMBIBITION PROCESS AND WATER STATUS OF MAIZE SEED DURING GERMINATION}

\begin{abstract}
This study examined the imbibition process and the water status of maize seed and excised embryos during seed germination. Two maize seed lots, cultivars Zeneca 8330 and 8420, were tested by germination, accelerated ageing, electrical conductivity, cold test and field seedling emergence to identify the initial physiological quality of each seed lot and to determine the relationship of the pathway of water uptake and seed quality. Seeds were hydrated between six layers of paper towel, inside a plastic box, at $25^{\circ} \mathrm{C}$. Seed moisture was determined by the weighing samples of 100 seeds each and by the oven method $\left(105 \pm 3^{\circ} \mathrm{C} / 24 \mathrm{~h}\right)$. Seed water potential was determined by the hygrometric method through the use of a thermocouple. It was concluded that the embryo absorbs less water than the endosperm during the imbibition process. The rates of seed water uptake are related to physiological quality, as low vigour seed lot increased in moisture content faster than that of high quality. In contrast, the water potential was not affected by seed quality and cultivar. These findings suggest that the water status of seed plays a regulatory role in seed germination.
\end{abstract}

Index terms: Zea mays, imbibition, water potential, physiological quality.

\footnotetext{
${ }^{1}$ Aceito para publicação em 04.07.2003.

${ }^{2}$ UFPel/FAEM/Depto de Fitotecnia; Cx. Postal 354, 96010-900, Pelotas, RS; e-mail: bloisvillela@uol.com.br

${ }^{3}$ USP/ESALQ/Depto de Produção Vegetal; Cx. Postal 09, 13418-900,

Piracicaba, SP; e-mail: jmarcos@carpaciagri.usp.br; adlcnove@carpa.ciagri.usp.br

${ }^{4}$ Bolsista CNPq.
} 


\section{INTRODUÇÃO}

Os mecanismos bioquímicos e fisiológicos do metabolismo do processo de germinação, iniciados com a embebição e que se estendem até a emissão da raiz primária, variam conforme o nível de hidratação da semente. O processo de hidratação é caracterizado, inicialmente, por rápida absorção de água e acelerado aumento do potencial hídrico do embrião, seguido de redução acentuada na velocidade de hidratação. Ao alcançar um teor de água, similar ao da maturidade fisiológica, a semente novamente apresenta pronunciada velocidade de absorção de água (Labouriau, 1983; Bewley \& Black, 1994 e Bradford, 1994). Por outro lado, há registros de que, no início do crescimento visível do eixo embrionário, o potencial hídrico do embrião atinge patamar semelhante ao verificado na maturidade fisiológica (Westgate, 1994 e Egli \& TeKrony, 1997).

A velocidade de hidratação depende da disponibilidade hídrica, potencial mátrico do substrato, potencial osmótico da solução que umedece o substrato, temperatura e características intrínsecas da semente, tais como, tamanho, composição química, permeabilidade da cobertura protetora, teor de água inicial e qualidade fisiológica (Vertucci \& Leopold, 1983; Popinigis, 1985).

Diferentes estruturas da semente de milho não absorvem água com velocidades similares. A cobertura protetora reidrata com velocidade inferior às demais estruturas. $\mathrm{O}$ embrião absorve com maior velocidade e de forma contínua, em razão do alongamento e da divisão celular. O endosperma, por outro lado, reidrata a uma velocidade intermediária (Bewley \& Black, 1994; McDonald et al., 1994).

No reinicio do crescimento embrionário, a semente de milho, atinge teor de água de 30-35\%, enquanto o embrião e o endosperma alcançam respectivamente, 50 a $55 \%$ e 25 e 30\% (McDonald et al., 1994). Nas sementes dessa mesma espécie, Egli \& TeKrony (1997) verificaram equivalência de potenciais hídricos no embrião, entre a maturidade fisiológica e o reinicio do crescimento embrionário, que alcançou -2,0 MPa.

A água na semente pode ser caracterizada por um estado energético, descrito, de forma conveniente, pelo potencial total de água, função aditiva dos potenciais de pressão, osmótico e matricial que, apresentado na forma de energia por unidade de volume, pode ser expresso em unidades de medida de pressão (Villela, 1998).

De forma genérica, entre espécies, conforme o cultivar e as condições ambientais reinantes, ocorrem diferenças apre- ciáveis no teor de água da semente na maturidade fisiológica e na retomada do crescimento embrionário. Entretanto, o potencial hídrico do embrião ou do eixo embrionário parece não apresentar variações acentuadas entre as espécies, nesses dois estádios. Desta forma, Bradford (1994) e Egli \& TeKrony (1997), considerando essa similaridade de potenciais hídricos, sugerem que o estado da água possa representar papel regulador no desenvolvimento e na germinação da semente.

A pesquisa foi desenvolvida com o objetivo de estudar as modificações do estado energético da água na semente de milho no processo de germinação, com destaque para o comportamento do potencial hídrico do embrião e do teor de água da semente inteira e de suas estruturas funcionais.

\section{MATERIAL E MÉTODOS}

O trabalho foi conduzido no Laboratório de Sementes do Departamento de Produção Vegetal da Escola Superior de Agricultura “Luiz de Queiroz”(ESALQ), da Universidade de São Paulo (USP), em Piracicaba, SP.

Foram utilizadas sementes de milho (Zea mays L.), tamanho 20 (retenção na peneira de perfuração redonda 20/ 64), cultivares Zeneca 8330 (híbrido triplo) e Zeneca 8420 (híbrido simples), cada um representado por dois lotes com diferentes potenciais fisiológicos.

Para a obtenção de dois níveis de qualidade fisiológica, cada lote foi dividido em duas partes, sendo uma (lotes 1 e A) mantida em câmara fria e seca $\left(10^{\circ} \mathrm{C}\right.$ e UR $\left.45 \%\right)$ e, a outra (lotes 2 e B) submetida ao envelhecimento acelerado a $41^{\circ} \mathrm{C}$, por $48 \mathrm{~h}$; após esse período, as sementes foram submetidas a secagem natural, à sombra, por seis dias.

Visando a caracterização da qualidade inicial das sementes, foram realizadas as seguintes determinações:

a) Grau de umidade: determinado pelo método da estufa a $105 \pm 3^{\circ} \mathrm{C}$, durante $24 \mathrm{~h}$, utilizando duas amostras por lote (Brasil, 1992). Os resultados foram expressos, em base úmida, em gkg $^{-1}$.

b) Germinação: quatro subamostras de 50 sementes para cada lote, foram semeadas em rolo de papel toalha, umedecido com um volume de água equivalente a 2,5 vezes o peso do substrato seco. $\mathrm{O}$ germinador foi regulado à temperatura de $25^{\circ} \mathrm{C}$ e as avaliações realizadas aos quatro e sete dias após a semeadura (Brasil, 1992).

c) Envelhecimento acelerado: conduzido em caixas plásticas, contendo $40 \mathrm{~mL}$ de água e uma camada uniforme de sementes dispostas sobre a superfície da tela, mantidas em incubadora a $41^{\circ} \mathrm{C}$, por $96 \mathrm{~h}$. Após o período de envelhecimen- 
to, quatro subamostras de 50 sementes foram submetidas à germinação, conforme descrito no item b, sendo a avaliação realizada aos quatro dias após a instalação deste teste.

d) Condutividade elétrica: quatro subamostras de 50 sementes por lote, previamente pesadas, imersas em $75 \mathrm{~mL}$ de água destilada, a $25^{\circ} \mathrm{C}$. Após a hidratação por 24 horas, foi realizada a leitura da condutividade elétrica da solução e, os resultados, expressos em $\mu \mathrm{Scm}^{-1} \mathrm{~g}^{-1}$.

e) Teste de frio sem solo: realizado de maneira semelhante ao teste de germinação; todavia, antes de serem colocados no germinador, os rolos permaneceram a $10^{\circ} \mathrm{C}$, durante sete dias. A avaliação foi realizada no quarto dia, conforme as condições descritas no item b.

f) Emergência das plântulas em campo: quatro subamostras de 100 sementes por lote, foram distribuídas em sulcos de 4 m de comprimento, a $5 \mathrm{~cm}$ de profundidade, e cobertas com uma fina camada de terra. As avaliações foram realizadas aos 15 dias após a semeadura, determinando-se as porcentagens de emergência de plântula.

O estabelecimento da marcha de absorção de água foi realizado com quatro subamostras de 100 sementes de cada lote submetidas à hidratação sob condições de plena disponibilidade hídrica, pelo método do substrato úmido, de acordo com Rossetto et al. (1997). As sementes de cada amostra, previamente pesadas, foram distribuídas entre duas camadas de papel toalha, cada uma composta de seis folhas, umedecidas com um volume de água equivalente a 2,5 vezes o peso do substrato seco e colocadas sobre a tela das caixas plásticas. As caixas, tampadas e contendo $40 \mathrm{~mL}$ de água, foram mantidas em germinador, a $25^{\circ} \mathrm{C}$.

O grau de umidade das sementes e de suas partes (embrião e cariopse sem embrião), de cada subamostra, foi monitorado periodicamente, em intervalos regulares de $3 \mathrm{~h}$ ao longo das primeiras 12 h e em intervalos de 6 h, entre 12 e 48 h, durante o processo de hidratação, num total de 11 momentos de avaliação, para cada lote.

Os graus de umidade das sementes inteiras foram obtidos pela pesagem de 100 sementes, no transcurso do processo de hidratação. Os embriões e as cariopses sem embrião foram extraídos de 10 sementes, em uma sala com ambiente controlado $\left(10^{\circ} \mathrm{C}\right.$ e 85 a $90 \%$ UR) e os graus de umidade determinados em estufa a $105 \pm 3^{\circ} \mathrm{C}$, por $24 \mathrm{~h}$ (Brasil, 1992), sendo os resultados expressos em base úmida.

O monitoramento do potencial hídrico foi conduzido periodicamente, em intervalos de $6 \mathrm{~h}$, no decorrer das primeiras $48 \mathrm{~h}$ do processo de hidratação, totalizando oito momentos de avaliação.
Para a determinação do potencial hídrico, embriões extraídos de quatro sementes, em uma sala com ambiente controlado $\left(10^{\circ} \mathrm{C}\right.$ e 85 a $90 \%$ UR), foram, imediatamente após, mantidos em câmara de amostra C-52, marca Wescor, por um período de $3 \mathrm{~h}$ para alcançar o equilíbrio, a $25^{\circ} \mathrm{C}$. Após esse período, o potencial hídrico foi avaliado em psicrômetro termopar, tipo multivoltímetro, Wescor HR-33T, operando no método de ponto de orvalho, conforme Egli \& TeKrony (1993).

A análise estatística dos resultados da avaliação do potencial fisiológico das sementes, de cada cultivar, foi feita utilizando-se o delineamento inteiramente casualizado, com quatro repetições para cada lote. Os dados relativos à avaliação da absorção de água das sementes e suas estruturas e do potencial hídrico dos embriões, durante o período de hidratação, foram submetidos à análise de regressão polinomial.

\section{RESULTADOS E DISCUSSÃO}

Os dados médios referentes às determinações para a avaliação da qualidade das sementes de milho, cultivares Zeneca 8330 (lotes 1 e 2) e Zeneca 8420 (lotes A e B), apresentados na Tabela 1, mostram similaridade entre os quatro lotes no teste de germinação e superioridade dos lotes 1 e A em relação aos lotes 2 e B, nos testes de envelhecimento acelerado, condutividade elétrica e emergência das plântulas em campo, evidenciando a eficiência do envelhecimento artificial para a obtenção de lotes com diferentes potenciais fisiológicos.

TABELA 1. Dados médios obtidos para as determinações do grau de umidade - GU ( $\left.\mathrm{gkg}^{-1}\right)$, germinação - TG (\%), envelhecimento acelerado - EA (\%), condutividade elétrica - CE $\left(\mu \mathrm{Scm}^{-1} \mathrm{~g}^{-1}\right)$, frio sem solo - FSS (\%) e emergência das plântulas em campo - EPC (\%), de dois lotes de sementes de milho, cultivares Zeneca 8330 (lotes 1 e 2) e Zeneca 8420 (lotes A e B).

\begin{tabular}{crrrrr}
\hline \multirow{2}{*}{ Determinações } & \multicolumn{2}{c}{ Zeneca 8330} & & \multicolumn{2}{c}{ Zeneca 8420} \\
\cline { 2 - 3 } \cline { 6 - 7 } & Lote 1 & Lote 2 & & Lote A & Lote B \\
\hline GU & $89,00 \mathrm{a}^{*}$ & $104,00 \mathrm{a}$ & & $92,00 \mathrm{a}$ & $105,00 \mathrm{a}$ \\
TG & $97,00 \mathrm{a}$ & $98,00 \mathrm{a}$ & & $97,00 \mathrm{a}$ & $98,00 \mathrm{a}$ \\
$\mathrm{EA}$ & $70,00 \mathrm{a}$ & $51,00 \mathrm{~b}$ & & $69,00 \mathrm{a}$ & $59,00 \mathrm{~b}$ \\
$\mathrm{CE}$ & $15,28 \mathrm{a}$ & $29,26 \mathrm{~b}$ & & $13,48 \mathrm{a}$ & $23,10 \mathrm{~b}$ \\
FSS & $99,00 \mathrm{a}$ & $95,00 \mathrm{a}$ & & $99,00 \mathrm{a}$ & $96,00 \mathrm{a}$ \\
EPC & $93,00 \mathrm{a}$ & $83,00 \mathrm{~b}$ & & $93,00 \mathrm{a}$ & $85,00 \mathrm{~b}$ \\
\hline
\end{tabular}

* Médias seguidas pela mesma letra, na linha, para cada cultivar, não diferem pelo teste de Tukey, em nível de $5 \%$ de probabilidade. 
Resultados da marcha de absorção de água por embriões, cariopses sem embrião e sementes de milho, apresentados nas Figuras 1 e 2, indicam que a semente inteira e cada estrutura funcional absorveram água de forma similar ao padrão trifásico, apresentado por Labouriau (1983) e Bewley \& Black (1994), embora, para sementes e cariopses sem embrião, não tenha ocorrido pronunciado aumento na absorção de água no início da Fase 3. As sementes apresentaram, nas primeiras nove horas, rápida absorção de água, alcançando teores inferiores a $200 \mathrm{gkg}^{-1}$, com ganho de 60 a $70 \mathrm{gkg}^{-1}$ nas primeiras três horas e de 45 a $50 \mathrm{gkg}^{-1}$ entre três e nove horas, dependendo do cultivar e lote. Entre nove e trinta e seis horas, as sementes tiveram aumentos menos acentuados até 285 a $295 \mathrm{gkg}^{-1}$, quando ocorreu o início do crescimento visível do eixo embrionário. Resultados semelhantes foram observados por
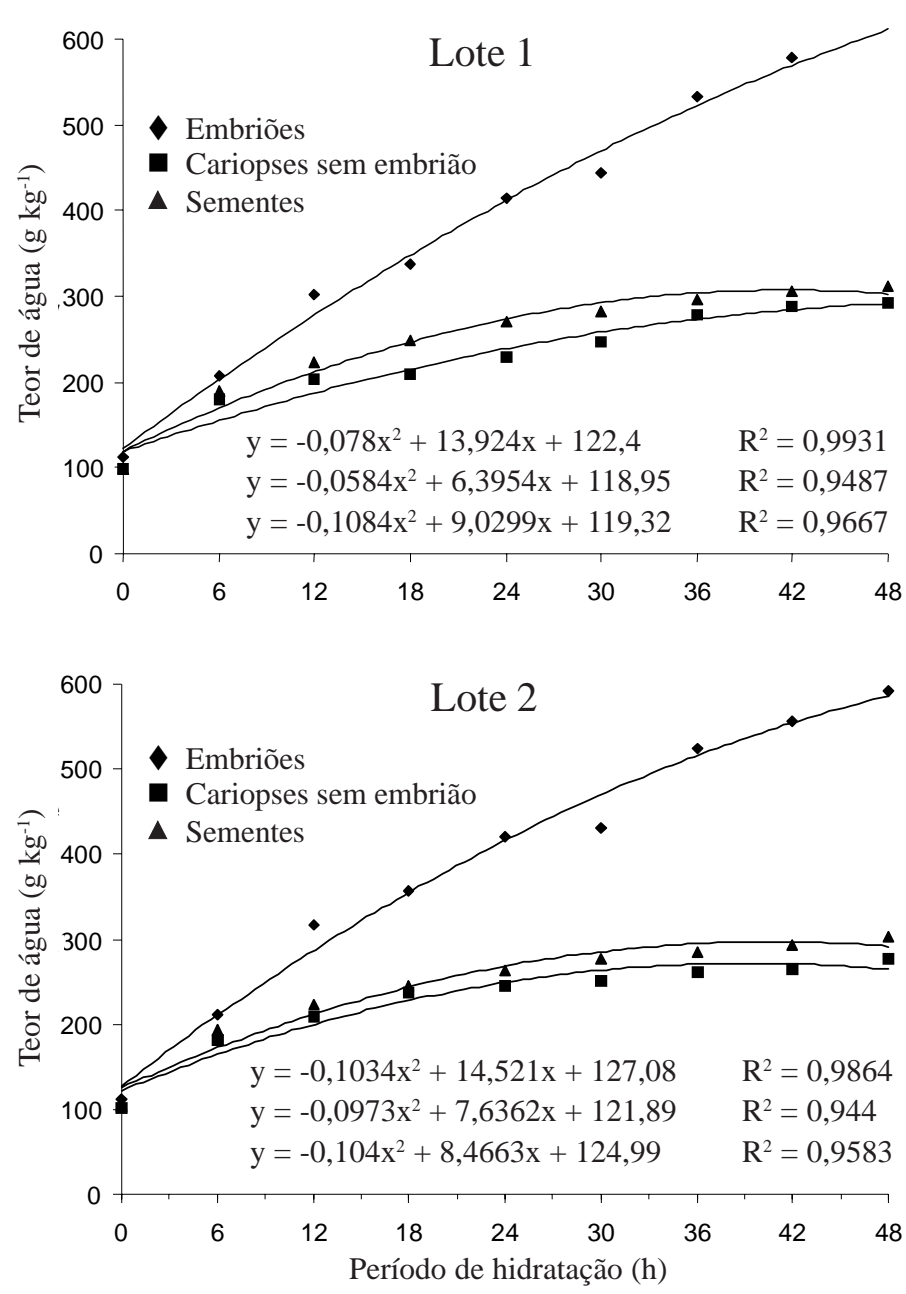

FIG. 1.Marcha de absorção de água de embriões, cariopses sem embrião e sementes de milho, cultivar Zeneca 8330, lotes 1 e 2 .
McDonald et al. (1994) e Egli \& TeKrony (1997), ao determinarem que, no início da emissão da raiz primária, as sementes de milho apresentavam teores de água de 310 a $332 \mathrm{~g} \mathrm{~kg}^{-1}$, após 24 e 38 h de hidratação, respectivamente. Essa discrepância no tempo necessário para atingir a Fase 3 , pode ser atribuída às diferentes metodologias empregadas na hidratação das sementes.

Com referência à marcha de absorção de água de cariopses sem embrião, não foram observadas diferenças marcantes entre lotes e entre cultivares.

Os embriões apresentaram, após nove horas de hidratação, teores de água de 240 a $260 \mathrm{gkg}^{-1}$ e, no início da fase de crescimento visível do eixo embrionário, entre 500 e $530 \mathrm{gkg}^{-1}$. Desta forma, após $36 \mathrm{~h}$ de hidratação, a quantidade de água absorvida pelos embriões atingiu valor igual à sua massa de matéria seca.
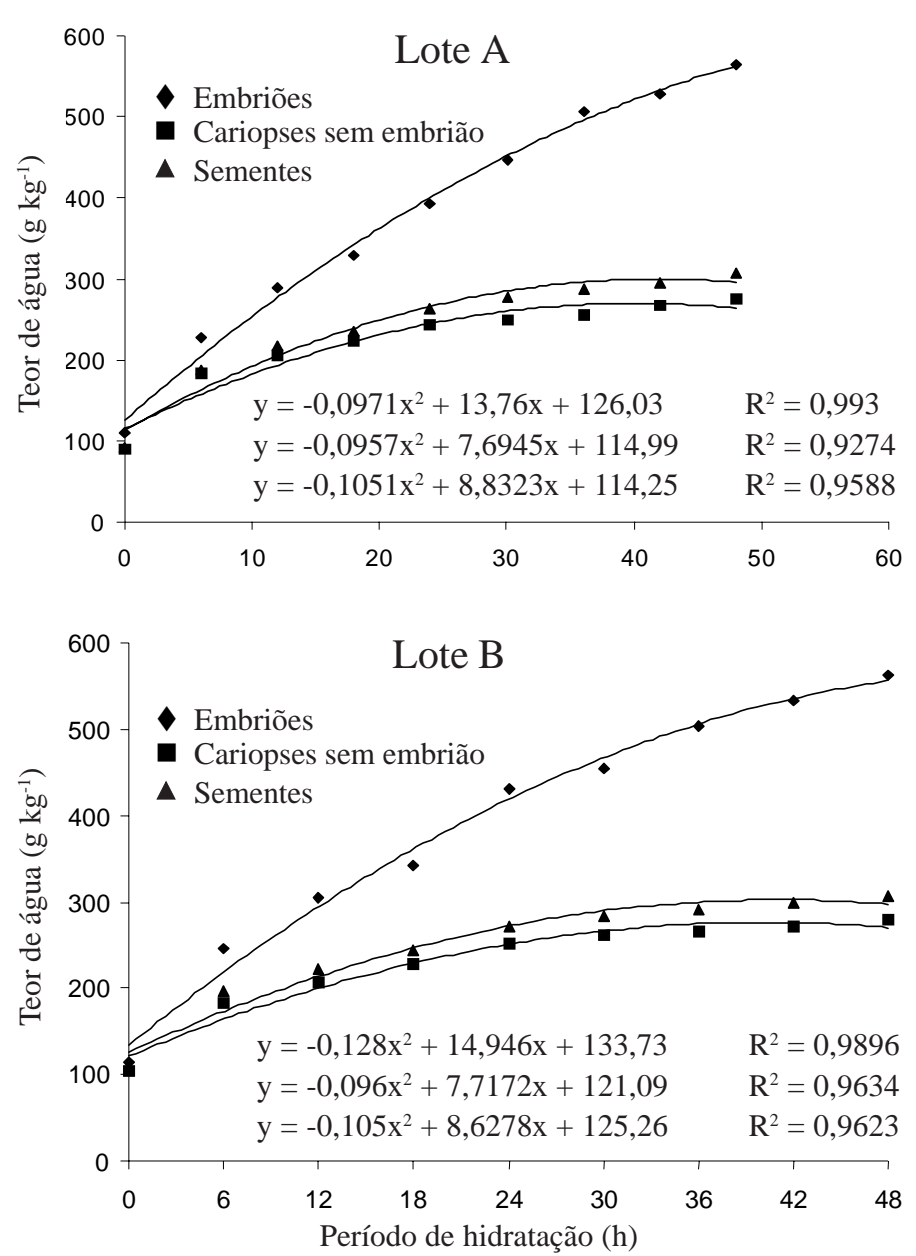

FIG. 2. Marcha de absorção de água de embriões, cariopses sem embrião e sementes de milho, cultivar Zeneca 8420, lotes A e B. 
Numa análise conjunta, verificou-se que o embrião absorveu água com velocidade superior à da cariopse sem embrião, em função, conforme McDonald et al. (1994), de diferenças de composição química, de morfologia e de permeabilidade da cobertura protetora dessas estruturas funcionais. Por outro lado, a cariopse sem embrião absorveu maior quantidade de água que o embrião, decorrente do fato daquela estrutura representar sete a oito vezes a massa do embrião.

De forma comparativa, constatou-se que, na Fase 1, entre zero e nove horas de hidratação, os embriões extraídos das sementes dos lotes de menor potencial fisiológico (lotes 2 e B) absorveram maior quantidade de água. Entretanto, na Fase 2, a maior absorção de água ocorreu nos embriões retirados das sementes dos lotes de maior qualidade (lotes $1 \mathrm{e}$ A). Esta ocorrência, talvez, possa ser atribuída à maior intensidade dos processos metabólicos, nas sementes de maior potencial fisiológico, visando assegurar condições para o crescimento do embrião. Vale lembrar que, os processos de digestão de macromoléculas armazenadas, mobilização de compostos de cadeia mais simples e assimilação de substâncias complexas, envolvem consumo de quantidade considerável de água.

Esta constatação vem ao encontro da afirmação de Labouriau (1983) que o processo de hidratação ocorre em duas fases sucessivas: a embebição, processo físico-químico determinado pelo potencial matricial da semente e a absorção de água associada ao metabolismo respiratório.

A análise geral dos dados relativos à marcha de absorção de água permite constatar que o embrião reidrata-se com velocidade superior à da cariopse sem embrião, enquanto a semente absorve água com velocidade intermediária. Por outro lado, entre o final da embebição e o início da retomada do crescimento embrionário, embriões de sementes de maior potencial fisiológico absorvem maior quantidade de água que os embriões de sementes de menor qualidade.

A Figura 3 mostra que o potencial hídrico do embrião, inicialmente baixo, apresentou elevação conforme aumentou o teor de água, de maneira mais pronunciada entre 6 e $18 \mathrm{~h}$. Após 12 h de hidratação, os embriões, com teores de água e potenciais hídricos próximos de 30\% e-4,0MPa, respectivamente, apresentaram, conforme o modelo dos múltiplos sítios de sorção de água pelas macromoléculas (Vertucci, 1993), água dos tipos 1, 2 e 3. Vale lembrar que nos teores de água (20 a 33\%) relativos à água tipo 3 ocorrem atividades catabólicas significativas, havendo a decomposição das substâncias de reserva.
Ao final de 18 e 24 h verificaram-se, de maneira geral, níveis de hidratação correspondentes à água do tipo 4, caracterizando a ocorrência de processos de biossíntese necessários à germinação, como a síntese protéica, conforme relataram Villela \& Marcos Filho (1998).

No início do crescimento visível do eixo embrionário, o embrião atingiu teor de água compatível com a do tipo 5, de ocorrência necessária à expansão e à divisão celular. $\mathrm{O}$ potencial hídrico do embrião alcançou patamar próximo de $-1,75$ a -2,15MPa. Resultados similares foram obtidos por Egli \& TeKrony (1997) ao verificarem que, na maturidade fisiológica e no início da emergência da raiz primária, os embriões de milho apresentaram potenciais hídricos equivalentes, situados entre -1,99 e -2,20MPa.
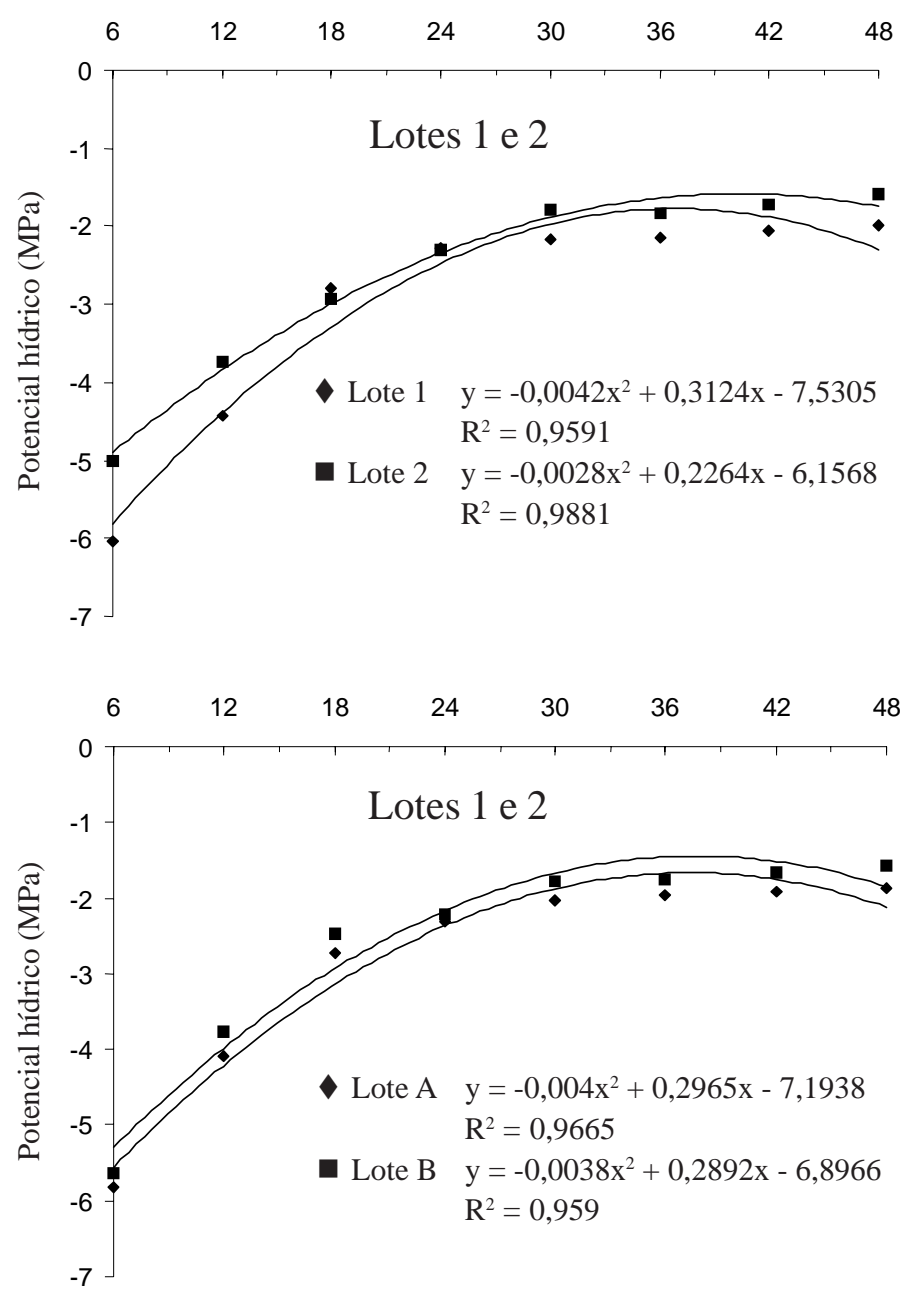

Períodos de hidratação (h)

FIG. 3.Alterações no potencial hídrico de embriões de sementes de milho, cultivar Zeneca 8330, lotes 1 e 2 e cultivar Zeneca 8420, lotes A e B. 
Na retomada do crescimento embrionário, o teor de água da semente difere acentuadamente entre espécies e pode variar entre cultivares, todavia, pesquisas recentes mostram que o potencial hídrico do embrião/eixo embrionário apresenta níveis semelhantes. Essa similaridade suporta a hipótese que o estado energético da água na semente apresenta papel regulatório na germinação (Egli \& TeKrony, 1993; Bradford 1994 e Egli \& TeKrony, 1997).

\section{CONCLUSÕES}

- O embrião hidrata-se com velocidade superior à da cariopse sem embrião, apesar de absorver menor quantidade de água;

- na fase de embebição, os embriões das sementes dos lotes de menor potencial fisiológico absorvem quantidade de água superior aos das sementes dos lotes de maior potencial fisiológico;

- na retomada do crescimento embrionário, ocorre similaridade de potenciais hídricos nos embriões, entre cultivares e entre lotes com diferentes potenciais fisiológicos.

\section{REFERÊNCIAS}

BEWLEY, J.D.; BLACK, M. Seeds Physiology of development and germination. New York: Plenum Press. 445 p. 1994.

BRADFORD, K.J. Water stress and the water relations of seed development: a critical review. Crop Science, v.34, p.1-11, 1994.

BRASIL, Ministério da Agricultura. Regras para análise de sementes. Brasília: Departamento Nacional de Produção Vegetal, 1992. $365 \mathrm{p}$.

EGLI, D.B.; TEKRONY, D.M. Germination and water relations of immature soybean seed. Seed Science and Technology, v.21, p.139148, 1993.

EGLI, D.B.; TEKRONY, D.M. Species differences in seed water status during seed maturation and germination. Seed Science Research, v.7, p.3-11, 1997.

LABOURIAU, L.G. A germinação das sementes. Washington: OEA. 174p. 1983.

McDONALD, M.B. JR.; SULLIVAN, J.; LAUER, M.J. The pathway of water uptake in maize seeds. Seed Science \& Technology, v.22, p.79-90, 1994.

POPINIGIS, F. Fisiologia da semente. Brasília:AGIPLAN, 1985. $289 \mathrm{p}$.

ROSSETTO, C.A.V. et al. Comportamento da semente de soja durante a fase inicial do processo de germinação. Scientia Agricola, v. 54, n.1 / 2, p.106-115, 1997.

VERTUCCI, C. Predicting the optimum storage condition for seeds using thermodynamic principles. Journal Seed Technology. Lansing, v.17, n.2, p.41-53, 1993.

VERTUCCI, C.W.; LEOPOLD, A.C. Dynamics of imbibition of soybean embryos. Plant Physiology, v.72, p.190-193, 1983.

VILLELA, F.A. Water relations in seed biology. Scientia Agricola, v.55 (Especial), p.98-101, 1998.

VILLELA, F.A; MARCOS FILHO, J. Estados energéticos e tipos de água na semente. Revista Brasileira de Sementes, v.20, n.2, p.317-321, 1998.

WESTGATE, M.E. Water status and development of the maize endosperm and embryo during drought. Crop Science, v.34, p.7683, 1994. 